\title{
Left Sided Amyand's Hernia with Sliding Component
}

\author{
Ashis Pun, ${ }^{1}$ Roshan Khatri ${ }^{1}$ \\ ${ }^{1}$ College of Medical Sciences Teaching Hospital, Bharatpur, Chitwan, Nepal
}

\section{ABSTRACT}

The eponym 'Amyand hernia' coined in recognition of Claudius Amyand, the first surgeon to successfully perform appendectomy in a hernia sac containing appendix, refers to the vermiform appendix within inguinal hernia.

Here, we present a rare case, of Amyand's hernia in an 18 month-old boy who was brought with an inguino-scortal swelling which later on exploration was left sided Amyand's hernia with sliding component.

Amyand's hernia is not very often seen in the clinical practice and its pre-operative diagnosis is very difficult hence awareness of this disease condition is essential for preoperative suspicion and even diagnosis of the condition.

Keywords: Amyand's hernia; acute appendicitis; hernial repair.

\section{INTRODUCTION}

Claudius Amyand (1680-1740) performed the first documented and successful appendectomy on an 11year old boy in 1735 AD where he found a perforated appendix vermiformis in a hernial sac. ${ }^{1}$

We report a case of left sided Amyand's hernia along with sliding hernia of sigmoid colon in an 18 month old boy, who presented with left sided irreducible inguinal hernia. Appendicectomy followed by herniotomy was done and patient had uneventful recovery.

\section{CASE REPORT}

An 18 month-old boy was brought to emergency department of our centre, with complaints of pain and swelling in left groin of 6 hours duration. There was history of one episode of non- bilious vomiting. Vitals were within the normal limits. On abdominal examination, there was no abdominal distension and no visible peristalsis. Bowel sounds were audible and normal. On local examination tender, irreducible left sided inguino-scrotal swelling was present (Figure 1). Cough impulse could not be seen. There were no scrotal changes and testis was palpable. So, provisional diagnosis of left sided irreducible inguinal hernia was made and decision of operation was made.

Correspondence: Dr. Roshan Khatri, College of Medical Sciences Teaching Hospital, Bharatpur, Chitwan, Nepal. Email: roshankhatri@ gmail.com, Phone: 9851131822. 


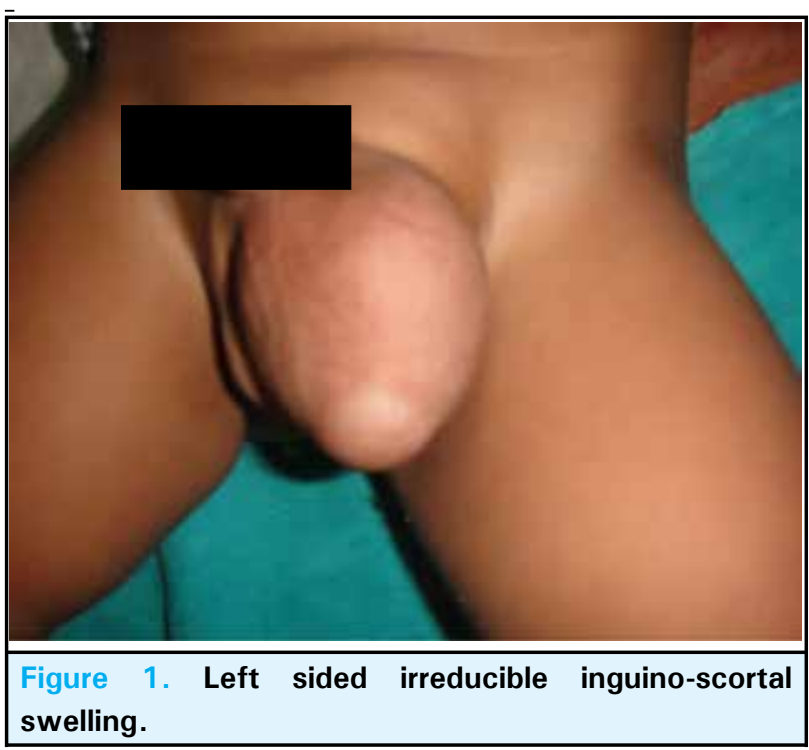

Exploration under general anaesthesia with left transverse inguinal incision was done. Hernia sac was identified and sigmoid colon was seen as sliding component of hernia (Figure 2). On opening the sac long inflamed appendix $(12 \mathrm{~cm})$ was found as content of hernia (Figure 3). Serosanguinous fluid was present. The cecum was found to be mobile and was lying in left iliac fossa. Appendicectomy was done through the same incision. There was no feature of strangulation of the contents. After herniotomy careful reduction of sliding component was done under vision avoiding injury to the sigmoid colon. Post-operatively intravenous broad-spectrum antibiotic was used for 5 days and the post-operative period was uneventful.

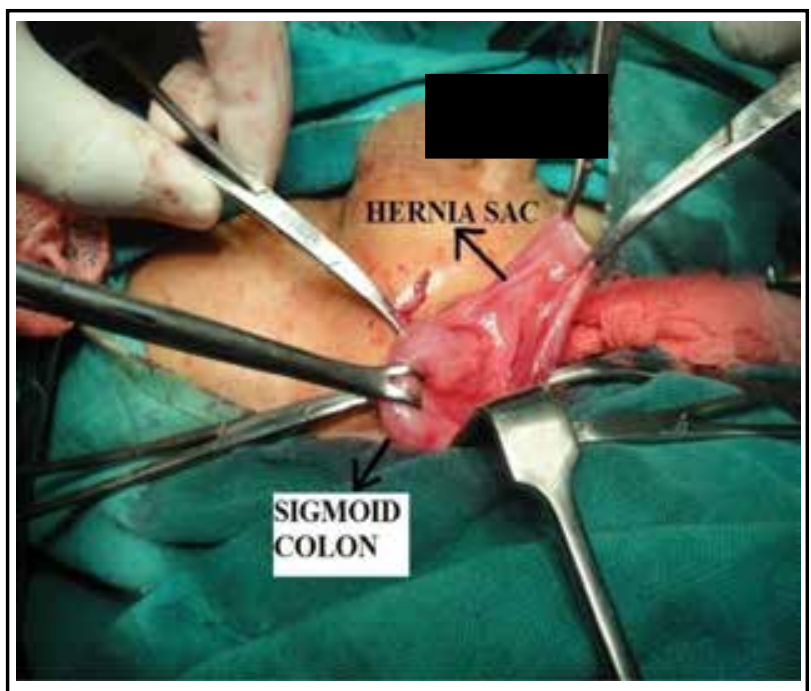

Figure 2. Hernia sac and sigmoid colon.

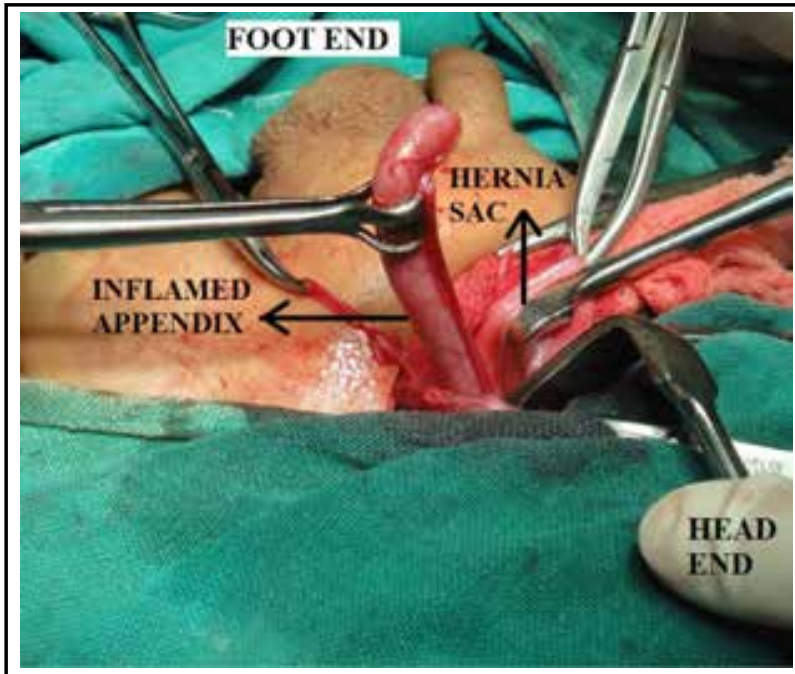

Figure 3. Inflamed appendix.

\section{DISCUSSION}

The term Amyand's hernia is used for depicting the condition of non-inflamed appendix, inflamed appendix or perforated appendix within an inguinal hernia. ${ }^{2}$ The Amyand's hernia in adults is rare and with less than $1 \%$ prevalence. The incidence of having a normal appendix within the hernial sac varies from $0.5 \%$ to $1 \%$, whereas only $0.1 \%$ of all cases, acute appendicitis is present in an inguinal hernia. ${ }^{3}$ Yagnik VD, reported that, in extensive literature search till April 2012 approximately 12 cases of left-sided Amyand hernia had been reported including his case report of two cases. ${ }^{4}$

Amyand's hernia is commoner in men and is almost exclusively right sided, most likely due to the usual anatomical position of the appendix, although there have been reports of left sided Amyand's hernia and in such cases there is usually an associated situs inversus, mobile caecum or intestinal malrotation. ${ }^{3}$ Perforated appendix and appendicular abscess finding within inguinal hernia sac is extremely rare clinical entity.

In our case, we also found a left sided Amyand's hernia which is one of the rare presentation in itself. Besides, it was associated with sliding component of sigmoid colon. Left side occurrence of appendix in our case was due to the presence of mobile cecum. Such a case of left sided Amyand's hernia along with sliding component is extremely rare.

Amyand's hernia is commonly misdiagnosed as an ordinary incarcerated hernia. Symptoms mimicking appendicitis may occur. Pre-operative diagnosis of hernial appendicitis is very difficult and when it occurs it is usually diagnosed as strangulated inguinal hernia. ${ }^{5}$ 
In case of Amyand's hernia, diagnosis is almost always made intraoperatively. Radioimaging technique like USG and CT scan may be helpful in preoperative diagnosis but they are not always enough. ${ }^{4}$ Its accurate diagnosis can be substantiated only with high clinical suspicion, since the symptoms associated with this disease state vary considerably. The most common clinical presentation involves rapidly progressing tenderness over a previous external hernia site, evocative of a strangulation or incarceration in the absence of radiographic evidence of obstruction. ${ }^{6}$

In cases of appendiceal inflammation or perforation, treatment consists of a combination of appendectomy and hernia repair for adults whereas appendectomy and herniotomy for children. Placement of prosthetic mesh materials for hernia repair in the presence of pus or perforation is not recommended due to a high rate of chronic wound infection, mesh sepsis, extrusion and fistulae. ${ }^{7,8}$ Torino et al irrigate inguinal canal with antibiotics when prosthetic mesh were used in infected Amyand's hernia. ${ }^{9}$ Additionally, in cases of inflamed and perforated appendix use of postoperative intravenous broad spectrum antibiotic is also recommended.

Amyand's hernia is rare entity and left sided Amyand hernia with sliding component is extremely rare condition. Surgery is the only modality of treatment, and use of antibiotics should depend upon the intraoperative finding of severity of appendicular inflammation. Although preoperative diagnosis of Amyand's hernia is very difficult but awareness of this condition will definitely help in preoperative suspicion of the disease and even early diagnosis because acute appendicitis is always a dire condition.

\section{ACKNOWLEDGEMENTS}

Department of Surgery, College of Medical Sciences Teaching Hospital, Bharatpur, Chitwan, Nepal.

\section{REFERENCES}

1. Amyand C. Of an inguinal rupture, with a pin in the appendix coeci, incrusted with stone; and some observations on wounds in the guts. Phil Trans Royal Soc. 1736;39:329-42.

2. Sharma H, Gupta A, Shekhawat NS, Memon B, Memon M. Amyand's hernia: A report of 18 consecutive patients over a 15-year period. Hernia. 2007;11:31-5.

3. Logan MT, Nottingham JM. Amyand's hernia: a case report of an incarcerated and perforated appendix within an inguinal hernia and review of the literature. Am Surg. 2001;67:628-9.

4. Yagnik VD. Amyand's hernia. J Indian Assoc Pediatr Surg. 2012;17(2):88.

5. D'Alia C, Lo Schiavo MG, Tonante A, Taranto F, Gagliano E, Bonanno L, et al . Amyand's hernia: case report and review of the literature. Hernia. 2003;7:89-91.
6. Davies MG, O'Byrne P, Stephens RB. Perforated appendicitis presenting as an irreducible inguinal hernia. Br J Clin Pract. 1990;44:494-5.

7. Delikoukos S, Tzovaras G, Liakou P, Mantzos F, Hatzitheofilou C. Late-onset deep mesh infection after inguinal hernia repair. Hernia. 2007;11:15-7.

8. van Geffen HJ, Simmermacher RK, van Vroonhoven TJ, van der Werken C. Surgical treatment of large contaminated abdominal wall defects. J Am Coll Surg. 2005;201:206-12.

9. Torino G, Campisi C, Testa A, Baldassarre E, Valenti G. Prosthetic repair of a perforated Amyand's hernia: hazardous or feasible? Hernia. 2007;11:551-2.

10. Priego P, Lobo E, Moreno I, Sánchez-Picot S, Gil Olarte MA, Alonso N, Fresneda V. Acute appendicitis in an incarcerated crural hernia: analysis of our experience. Rev Esp Enferm Dig. 2005;97(10):707-15. 